\title{
Radiological changes in carpal and metacarpal bones and phalanges caused by chain saw vibration
}

\author{
T. KUMLIN, M. WIIKERI, and P. SUMARI \\ Institute of Occupational Health, Helsinki, Finland
}

\begin{abstract}
Kumlin, T., Wiikeri, M., and Sumari, P. (1973). Brit. J. industr. Med., 30, 71-73. Radiological changes in carpal and metacarpal bones and phalanges caused by chain saw vibration. We have made a radiological examination of the shoulder and elbow joints, wrists, and hand bones of 35 lumberjacks, 30 of whom had used a chain saw for 7 to 20 years. Their average age was 43.9 years. Thirty-one men $(89 \%)$ had a history of typical attacks of Raynaud's phenomenon. In seven cases $(20 \%)$ with 10 to 18 years' exposure to chain saw vibration, the radiographs revealed vacuoles (defined in the paper) in the hand region, all between the styloid process of the ulna and the phalanges. The vacuoles are considered to be typical skeletal changes caused by long use of the chain saw. In the control group, which consisted of persons matched for age with the lumberjacks and who had never been exposed to vibration, no exactly corresponding skeletal changes were found. The nature and frequency of these findings are in keeping with similar results of other authors.
\end{abstract}

Skeletal changes in the upper limbs caused by protracted use of vibrating tools, mostly rock drills and riveting hammers, have been described since the 1930s. Changes are most often seen in the wrists and hands. In rock drillers, articular changes (Meiss, 1933), decalcification, vacuoles in the carpal bones (McLaren, 1937; Vainio, 1950; Hunter, 1964), and osteolysis of the distal phalanges (Wilson, McCormick, Tatum, and Creech, 1967) have been described. On the other hand, similar radiological examinations of miners using pickaxes and pneumatic rock drills (Casciu, Cossu, and Spinazzola, 1968) have not revealed any skeletal changes.

One of the newest vibrating tools, the chain saw, has been widely used since the end of the 1950s. Approximately 160000 motor saws are now in use in Finland. Technically, chain saws differ from pneumatic rock drills because they are smaller (the latest models weigh less than $10 \mathrm{~kg}$ ), the vibration frequency is generally greater, and the amplitude is smaller. The same kind of skeletal changes as those found in rock drillers have been seen in users of the motor saw-chronic atrophy and pseudocysts in the carpal bones (Horváth, Kákosy, and Villányi, 1969) and necrosis of the lunate, scaphoid, and triquetrum (de Larrard and Saldarkhan, 1970). The results of some examinations, however, have been normal (Barnes, Longley, Smith, and Allen, 1969).

We are publishing our findings because investigations regarding the chain saw are still relatively few and somewhat contradictory.

\section{Material and exposure to vibration}

Altogether we have examined 35 lumberjacks who have used a chain saw regularly for many years. All of them had been sent to our institute because of symptoms, suspected to be of occupational origin in the upper limbs. Their ages ranged from 33 to 58 years, the average 
being 43.9 years. Thirty $(85 \%)$ had used the saw for 7 to 20 years, $26(75 \%)$ worked with the saw for 8 to 12 months a year, and $30(85 \%)$ used it 20 to 29 days a month. It is further estimated that $28(80 \%)$ worked with it 5 to 9 hours per day.

\section{Control group}

For a control group we selected at random from the radiological archives of our institute for each lumberjack a person of the same age who had never been exposed to vibration in his work.

\section{Subjective symptoms connected with vibration}

When asked about subjective complaints connected with vibration of the saw, $18(51.5 \%)$ considered occasional numbness of the fingers to be the most unpleasant side effect, and $8(23 \%)$ put this complaint in second place. White fingers (Raynaud's phenomenon) were considered the most annoying symptom by $9(24 \%)$, and $7(20 \%)$ put this second. Only $4(11 \%)$ did not worry at all about white fingers. In all, $19(54 \%)$ noticed Raynaud's phenomenon 'often'. Only $2(5 \cdot 7 \%)$ considered pain in the writsts to be the worst symptom, and $4(11 \%)$ reported that pains in the elbow and shoulder joints were the worst. It is noteworthy that none of these complaints appeared if this tool had been used for from one month to one year, but after one to three years $4(11 \%)$, after four to six years $15(43 \%)$, and after 10 years $16(46 \%)$ had some of the complaints mentioned above.

\section{Radiological examinations, results, and comments}

All the lumberjacks had anteroposterior and lateral radiographs of the wrists, the metacarpal bones, and the phalanges. A special rapid processing film (Kodak $\mathrm{RP} / \mathrm{M}$ X-Omat) was used. When the radiographs were read special attention was paid to the following details: the bone density, the bone structure, the presence of

\section{TABLE}

\begin{tabular}{c|c|c|l}
\hline $\begin{array}{c}\text { Case } \\
\text { No. }\end{array}$ & Age & $\begin{array}{l}\text { Exposure } \\
\text { to vibra- } \\
\text { tion }(y r)\end{array}$ & Nature and location of changes \\
\hline 1 & 39 & 14 & $\begin{array}{l}\text { Vacuoles in distal end of left ulna } \\
\text { Vacuoles in distal end of left ulna } \\
\text { Vacuoles in distal end of left and } \\
\text { right ulnae (also similar changes } \\
\text { in both middle fingers) } \\
\text { Vacuole in middle phalanx of } \\
\text { right middle finger } \\
\text { Vacuole in styloid process of left } \\
\text { ulna } \\
\text { Changes typical of Kienboeck's } \\
\text { disease in both lunates and } \\
\text { vacuole in distal end of left } \\
\text { radius } \\
\text { Vacuoles in right scaphoid, capi- } \\
\text { tate, and hamate (Fig. la) } \\
\text { aacuoles in left scaphoid and } \\
\text { capitate and a small cyst in capi- } \\
\text { tate (Fig. 1b). }\end{array}$ \\
\hline 7 & 58 & 112 & $18-11$ \\
\hline
\end{tabular}

cysts $^{1}$, the presence of vacuoles ${ }^{2}$, the articular surfaces, and the soft tissues.

Changes that we would consider as typical of vibration were found in a total of seven men $(20 \%)$. The location and type of the changes, and the age and duration of exposure to vibration of these men were as shown in the Table.

${ }^{1}$ By 'cyst' we mean a small (2-3 mm diameter), circumscribed, radiolucent area, generally seen in the central part of the bone.

${ }^{2} \mathrm{~A}$ vacuole we regard as a bigger cyst (4-6 $\mathrm{mm}$ diameter) but situated juxta-articularly.

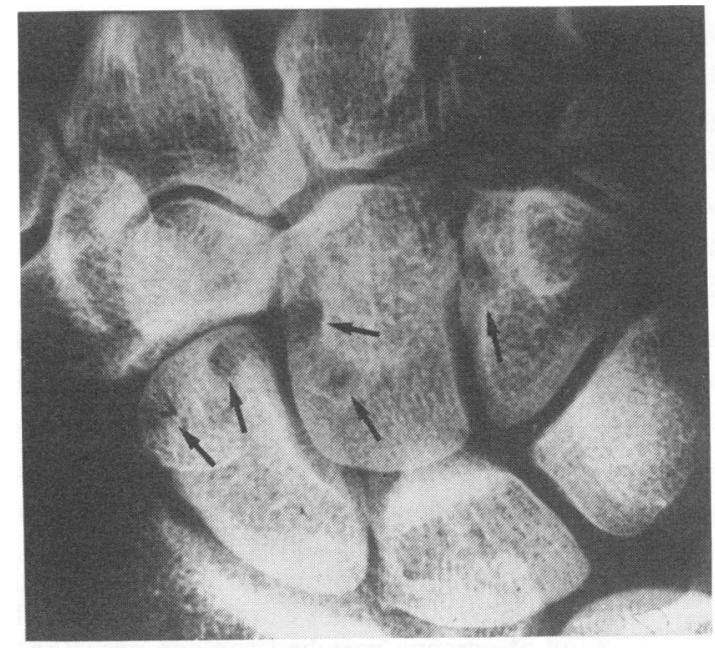

(a)

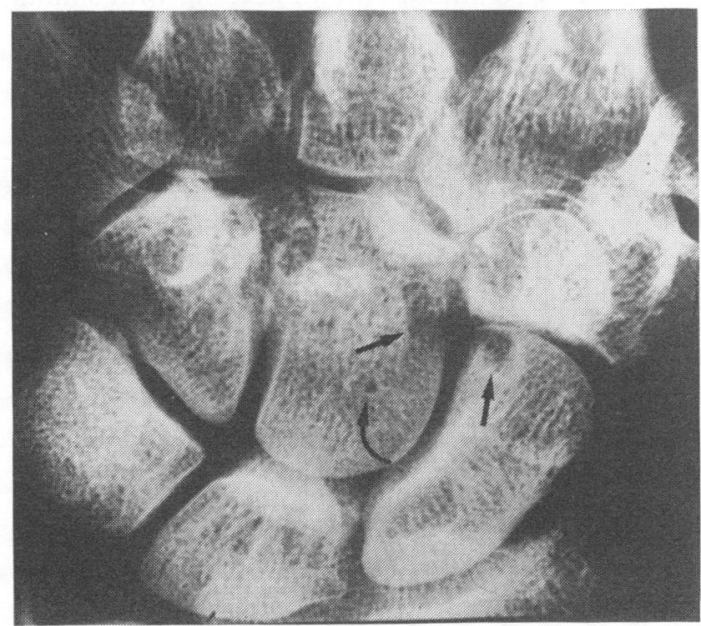

(b)

FIG. 1. Case 7. (a) Right wrist. Vacuoles in scaphoid, capitate, and hamate bones (arrows). (b) Left wrist. Vacuoles in scaphoid and capitate bones (straight arrows) and a small cyst in the capitate bone (curved arrow). 
In addition, three of the above-mentioned workers had arthrotic changes. In one case these were between the distal ends of the radius and ulna, in the second in the carpal region, and in the third in the distal interphalangeal joint of the little finger.

All these seven cases had had long exposure to chain saw vibration-10 to 18 years, average 13.8 years. Each had a history of one or more of the following typical subjective symptoms of the so-called vibration syndrome: attacks of Raynaud's phenomenon (4 cases), numbness of the fingers ( 3 cases), or pain in the wrists ( 2 cases).

As regards objective clinical findings, in four cases the motility of the wrists was remarkably decreased, and in six cases either the clinical neurological or neurophysiological investigation was abnormal.

All seven patients were recommended to avoid using any vibrating tools in the future.

In the control group radiological changes in the area of the hand were found in seven persons: three had marked osteoporosis in all the hand bones, two had arthrosis in the radius-ulna space, and two had cyst formations: one had a $72 \mathrm{~mm}$ diameter cyst in the left scaphoid and the other had cysts of about $3 \mathrm{~mm}$ diameter in both capitates.

\section{Discussion}

According to the literature the most typical radiological changes caused by vibrating tools are osteoporosis and cyst-like formations in the carpal bones. In this investigation the most outstanding findings have been that $20 \%$ of the lumberjacks examined had formations which we call vacuoles (see footnote 2 on page 72), in the area from the styloid process of the ulna to the phalanges.

Comparing the radiological changes in the lumberjacks with those in the non-exposed control group, the radiolucent formations in the exposed cases, the vacuoles, have a larger diameter, about 4 to $6 \mathrm{~mm}$. The diameter of the cysts in the controls is only 2 to $3 \mathrm{~mm}$. The location, too, is different: in the exposed group the vacuoles are, without exception, in a juxta-articular position, whereas in the control group the cysts are more in the central part of the bone. Moreover, those exposed to vibration seem to have a narrow sclerotic zone around the vacuoles. None of the lumberjacks had any osteoporosis or arthrosis, but one had changes typical of Kienboeck's disease in both lunates.

We therefore consider that vacuoles, particularly in the carpal region, are a pathognomic radiological change caused by vibration. These changes can be distinguished, by means of their location and size, from cysts that also may appear in the same skeletal region of persons not exposed to vibration.

Abnormal skeletal changes of this kind may be regarded as late results of a long process in which the vibration angiopathy, which is vasoconstrictive and even obliterative, is probably the primary cause. Hence the early vascular changes should, if possible, be revealed by circulation studies and arteriography of the upper limbs, particularly the hand region.

\section{References}

Barnes, R., Longley, E. O., Smith, A. R. B., and Allen, J. G. (1969). Vibration disease. Aust. med. J., 1, 901-905.

Casciu, G., Cossu, F. and Spinazzola, A. (1968). Sulla incidenza delle alterazioni radiologiche dell apparato osteoarticolare negli operai dell' industria estrativa sarda con particolare riguardo ai perforatori. Folia med. (Napoli), 51, 370-376.

Horváth, F., Kákosy, T. and Villányi, G. (1969). Structural changes of the carpal bones in motor saw workers. Magy. Radiol., 21, 257-266. (In Hungarian; English summary).

Hunter, D. (1964). The Diseases of Occupations, 3rd ed, p. 850. English Universities Press, London.

de Larrard, J., and Saldarkhan, P. (1970). Maladie de Kienboeck très invalidante chez un bûcheron landais. Arch. Mal. prof., 31, 330.

McLaren, J. W. (1937). Disability of workers using pneumatic drills. Lancet, 2, 1296.

Meiss, W. C. (1933). Gelenksveränderungen durch die Benutzung von durch Pressluft getriebenen Werkzeugen. Mschr. Unfallheilk. Invalidw., 40, 453-462.

Vainio, K. (1950). Om vibrationssyndrom, särskilt hos maskinborrare. Nord. hyg. T., 31, 249-267.

Wilson, R. H., McCormick, W. E., Tatum, C. F. and Creech, J. L. (1967). Occupational acroosteolysis. J. Amer. med. Ass., 201, 577-581.

Received for publication February 16, 1972. 